\title{
Therapy of gingival recessions using laterally positioned flap plus connective tissue graft: Case reports.
}

\author{
Isabela Fernandes-Benedito ${ }^{1}$, Márcio Eduardo Vieira-Falabella ${ }^{2^{*}}$
}

\author{
1. Bachelor of Science in Dentistry, Federal \\ University of Juiz de Fora, Brazil. Private practice. \\ 2. Phd in Periodontics, Associate Professor, Dental \\ Clinic Department in Faculty of Dentistry, Federal \\ University of Juiz de Fora, Brazil. ORCID: 0000- \\ 0002-3198-7472. \\ * Corresponding author: Márcio Eduardo Vieira \\ Falabella | Address: Paulo de Souza Freire St \\ 110/501 - Juiz de Fora - MG, Brazil, | Post code \\ 36025350. | Phone: +55 32988215415 | E-mail: \\ mevfalabella@hotmail.com \\ Work received on 20/04/2020. \\ Revised work: 17/06/2020 \\ Approved for publication on 14/07/2020
}

\begin{abstract}
Background: Gingival recession is an usual clinical condition with a multifactorial etiology, and its surgical treatment aims to improve aesthetics through root coverage, reducing dentin hypersensitivity, minimizing the risk of cervical caries, and increasing keratinized tissue. Objective: The aim of this study was to report the therapy used for two clinical cases of gingival recession in lower incisors. Methods: Miller class III and II gingival recessions were treated using the lateral flap associated with the connective tissue graft, with the maintenance of a keratinized tissue band in the tooth adjacent to the recession. Results: After 6 months a partial root coverage was obtained in the first case, above $70 \%$, and complete root coverage at second case, with increase of keratinized tissue in both. Conclusion: The lateral flap associated with a connective tissue graft showed an effective technique, with good results in root coverage, gain of keratinized tissue, reduction of hypersensitivity and satisfactory esthetics in the treatment of Miller's class II and III gingival recession.
\end{abstract}

KEY WORDS:

Gingival recession; Esthetics; Connective tissue.

Int. J. Inter. Dent Vol. . 14(1); 52-54, 2021.

\section{INTRODUCTION}

The gingival recession (GR) is the apical migration of the gingival margin beyond the cementum enamel junction, and recent surveys showed that $88 \%$ of people over 65 years and $50 \%$ of people with age between 18 and 64 years have at least one site with $\mathrm{GR}^{(1)}$.

GR has a multifactorial etiology and may be associated to periodontal disease, mechanical forces such as trauma due to inadequate tooth brushing or occlusal trauma. latrogenic factors such as uncontrolled orthodontic movements, poorly adapted partial dentures, and / or anatomical factors such as gingival biotype, aberrant frenulum attachments, presence of dehiscence and fenestration are also related. The diagnosis and control of these etiological factors are essential for the therapy of lesions that affect the mucogingival complex ${ }^{(2)}$.

The gingival recessions (GRs) result in exposure of the root, and their surgical treatment aims at aesthetic correction through root coverage, reduction of dentin hypersensitivity, minimizing the risk of cervical caries, and increase or create keratinized tissue (KT). The surgeries to increase KT generally allow for easily predictable results, and the prognosis of surgeries to obtain root coverage is excellent for GR Miller classes I and II, whereas for classes III or IV only partial root coverage is expected. The selection of a surgical technique depends on several factors, such as the size of the recession, the presence or absence of KT adjacent to the recession, the width and height of the interdental soft tissue, and the depth of the vestibule, among others are related to the patient ${ }^{(3)}$.

The main mucogingival surgical techniques include the use of the free autogenous gingival graft, which are best indicated for KT gain, but with unfavorable aesthetic results and low predictability of root coverage. The coronally positioned flap (CAF) or laterally positioned flap (LPF) isolated or associated with connective tissue graft (CTG), acellular dermal matrix, enamel matrix derivatives and guided tissue regeneration have the bests indications to root coverage ${ }^{(4)}$. The most frequently variable used to evaluate the clinical results is the amount of root coverage obtained, expressed as the difference between the baseline clinical attachment loss and the final data, and the percentage of complete root coverage ${ }^{(3)}$.

The best clinical results are obtained with CAF associated with CTG, considered the gold standard technique for having high predictability of root coverage ${ }^{(8)}$ due to both flap and periosteum nutrition ${ }^{(5)}$. CAF is the first choice for root coverage when there is adequate KT close to the recession defect. However, some local anatomical conditions may hinder the use of this technique, such as the absence of $\mathrm{KT}$, the presence of a very shallow vestibule and frenulum attachments, and the LPF technique may be indicated ${ }^{(6)}$.
Several modifications from the first report of LPF, such as marginal tissue exclusion and partial flap thickness have been described in order to reduce the risk of recession and dehiscence at the donor site. Since then, the technique has been reported as a treatment option for localized recession defects, resulting in increased KT and high degrees of root coverage $^{(7)}$

Tissue healing in GR with use of LPF shows the formation of long junctional epithelium and connective tissue with parallel fibers along previously exposed root surfaces ${ }^{(8)}$.

The LPF has a good aesthetic results, with the increased of KT and reduced root sensitivity. However, limitations of this technique include shallow vestibule, little inserted gum, and very wide recessions with root prominence ${ }^{(3)}$. LPF is an option for root coverage in localized GRs and has good results, with complete coverage of class I and II recessions in $62.5 \%$ of cases and partial coverage in $94 \%{ }^{(9)}$. The efficacy of LPF were evaluated among 120 patients with Miller class I and II GR and achieved $96 \%$ partial RC and $80 \%$ complete root coverage ${ }^{(6)}$.

Root coverage in Miller class III recessions, although with lower predictability, shows values between 54 and $85 \%$, and has its potential increased with the association of the $\mathrm{CTG}^{(3)}$. Using also the CTG + CAF or LPF, Cesar Neto et al (2019) ${ }^{(10)}$ showed an average coverage of $74 \%$ in class III recessions and Lee et al (2014) $)^{(11)}$ using LPF + CTG, also in class III recessions, showed coverage between 60 and $95 \%$.

Keratinized tissue gain is also an aim of mucogingival surgeries and the use of CTG enhances this increase that was reported in a systematic review of Miller class I and II GR therapy ${ }^{(12)}$

LPF is an option among mucogingival surgery techniques, which good results in root coverage and keratinized tissue gain. Thus, the aim of this study was to report two clinical cases of localized GRs using LPF associated with the CTG, and discuss the technique and the results obtained.

\section{CASE REPORTS}

The case reports were previously submitted and approved by the Research Ethics Committee of the Federal University of Juiz de Fora under the number 14111619.6.0000.5147.

\section{Case Report 1.}

Female, 43 years old, non-smoker without significant systemic changes, who finished orthodontic therapy about 2 years ago, with an aesthetic complaint and worried about possible tooth loss. Periodontal conditions were clinically assessed using the North Carolina periodontal 
probe (PC PUNC 15, Hu Friedy, IL, USA). The tooth 41 showed a GR = $10 \mathrm{~mm}$, Miller class III and Cairo class II, almost complete root exposure, absence of KT ("Figure 1a"), and with a visible proximal bone loss on radiographic image ("Figure $1 \mathrm{~b}$ "). The probing depth (PD) on buccal, mesial and distal surfaces $=2 \mathrm{~mm}$. The patient's periodontal phenotype is thick.

Scaling and root planning was performed with a Gracey 5-6 curette and then a partial thickness flap was made from the mesial of tooth 43 to the mesial of tooth 42 , preserving a margin of KT on the buccal face of this tooth. A connective tissue graft of the palate was obtained with the trap-door technique ${ }^{(13)}$ which was fixed to the root of tooth 41 with 5-0 Vicryl wire. Subsequently, the flap was positioned laterally over the graft and fixed with 4-0 silk thread ("Figure 1c"), which was removed 10 days later. Postoperative care included $0.12 \%$ chlorhexidine mouthwash and use of analgesic and anti-inflammatory drugs. The use of pre-surgical anti-inflammatory reduces morbidity after surgery, confirmed by the slight discomfort in the palatal area, reported by the patient. "Figure $1 \mathrm{~d}$ " shows the postoperative period at 15 days, and "Figure $1 \mathrm{e}$ " at six months, showing partial coverage (over $70 \%$, with a final $G R=3 \mathrm{~mm}$ ), and $\mathrm{KT}$ increase (gain of $4 \mathrm{~mm}$ ). At the final clinical examination, the PD on the buccal surface was $1 \mathrm{~mm}$, and in others surfaces $=2 \mathrm{~mm}$.

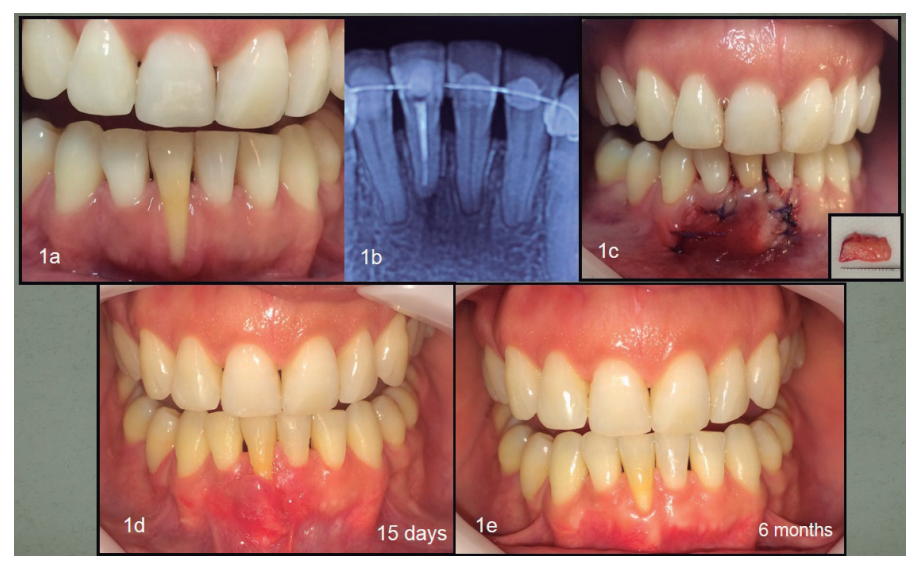

Figure 1.

\section{Case Report 2}

Female, 29 years old, non-smoker without significant systemic changes, with an aesthetic complaint and with a slight dentinal sensitivity, related to the tooth 31 . Periodontal conditions were clinically assessed using the North Carolina periodontal probe (PC PUNC 15, Hu Friedy, IL, USA). The tooth 31 showed a GR $=8 \mathrm{~mm}$ and $P D=1 \mathrm{~mm}$ on the buccal surface, Miller's class II and Cairo class I, absence of KT ("Figure 2a"), and with a slight loss in the bone proximal crests ("Figure $2 \mathrm{~b}$ "). The PD on buccal, mesial and distal surfaces $=2 \mathrm{~mm}$. The patient's periodontal phenotype is thick.

Scaling and root planning was performed with a Gracey 5-6 curette and then a partial thickness flap was made from the mesial of tooth 33 to the mesial of tooth 32, preserving a margin of KT on the buccal face of this tooth ("Figure $2 c$ "). A connective tissue graft obtained from the palate was obtained using the trap-door technique that was fixed to the root of tooth 31 with Vicryl 5-0 suture ("Figure $2 \mathrm{~d}$ "). Subsequently, the flap was positioned laterally over the graft and fixed with 4-0 silk sutures ("Figure 2e"), which was removed 10 days later. Postoperative care included $0.12 \%$ chlorhexidine mouthwash and use of analgesic and antiinflammatory drugs. In this clinical case, no postoperative morbidity was observed. "Figure $3 a$ " shows the postoperative period at 20 days and the "Figure 3b" at 45 days. The "Figure 3c" presents the clinical condition at six months, with $100 \%$ of root coverage $(\mathrm{GR}=0, \mathrm{PD}=1 \mathrm{~mm}$ on all surfaces), and gain of $\mathrm{KT}=4 \mathrm{~mm}$. The dentinal sensitivity disappeared.

\section{DISCUSSION}

The GR causes exposure of the root surface, resulting in dentinal hypersensitivity, shallow carious lesions, cervical abrasions and aesthetic demands ${ }^{(3)}$. Several mucogingival surgical approaches have the potential to correct GR defects by increasing the height and width of the KT. However, the success rate of these techniques in order to obtain a complete root coverage depends on some factors, such as defect classification, location ${ }^{(14)}$, extent, availability of apical or lateral KT, and technique used ${ }^{(2)}$.

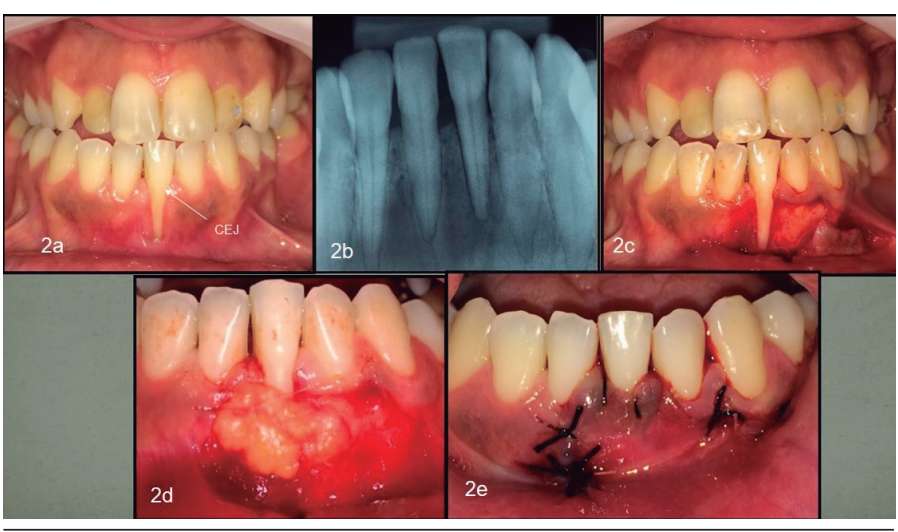

Figure 2.

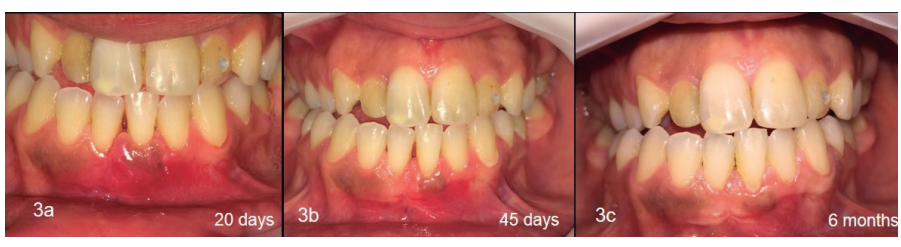

Figure 3.

The root coverage has numerous advantages, such as improved aesthetics, root protection against greater abrasion, and decreased dentin hypersensitivity ${ }^{(3)}$. In the two reported cases, the choice for the treatment of GR was the LPF associated with the CTG due to the presence of class II and another Miller class III recessions, both with no apical KT to the GR, which difficult the use of CAF, considered the gold standard technique(6).

Some modifications of the technique recommended by Grupe and Warren in 1956 have been proposed in search of a better prognosis for the donor tooth, such as the use of partial thickness pedicle flap, keeping the donor area covered by the periosteum. Chambrone et al $(1998)^{(14)}$ proposed maintaining a band of KT the donor tooth margin, which allowed few clinical changes in this area. These two technical modifications were performed in both reported cases to maintain a band of KT in the donor tooth, and for a better protection with the periosteum of the donor area, which remained without loss. Zucchelli \& Mounssif $(2015)^{(3)}$ suggested that the mesial-distal dimension of the flap should be $6 \mathrm{~mm}$ greater than the width of the GR measured at the level of the CEJ. In two cases a lateral flap twice of the width of the recession to be covered was maid, according to this conduct.

Root chemical conditioning aims to decontaminate and demineralize its surface, exposing the collagenous matrix of dentin and cementum, including citric and phosphoric acids. However, the results obtained with root demineralization have been controversial. In a study of patients with GR who were treated with CAF + CTG, the use of citric acid root conditioning did not determine significant differences in root coverage and $\mathrm{KT}$ increase ${ }^{(16)}$. There is no clear evidence that the use of root conditioning improves the clinical results in root coverage ${ }^{(3)}$. Thus, in the two reported cases no root chemical conditioning was performed, only mechanical root treatment.

In clinical examination after 6 months, both areas had an increase of $\mathrm{KT}$, and this fact may be justified by the associated use of the LPF and CTG technique, as described by Chambrone et al $(2008)^{(12)}$ who reported greater KT width gain with the use of CTG, providing significant root coverage and clinical attachment level increase, also corroborated by Zuchelli and Mounssif (2015) (3).

The root coverage obtained after 60 days was $70 \%$ in case 1 that showed a GR with $10 \mathrm{~mm}$ and almost complete root exposure, and $100 \%$ in case 2 which had an $8 \mathrm{~mm}$ recession, and these clinical appearances were maintained at 6 months. These root coverage results were associated with depth to shallow probing and absence of bleeding on probing. In case 1, partial coverage was obtained, which is consistent with the literature showing less predictable results in class III GR, with only partial defect coverage ${ }^{(3,10,11)}$. In case 2 , a class II GR, the complete coverage was obtained and is also in agreement with studies showing this possibility in this kind of periodontal defect ${ }^{(6,12)}$

The use of LPF associated with CTG was very effective in therapy of localized GRs, ensuring proper aesthetics, effective root coverage and decreased sensitivity. The success of this surgical technique was directly 
related to the appropriate gingival conditions of the lateral donor tooth, allowing for a highly effective and predictable surgical technique.

\section{CONCLUSION}

The LPF plus CTG has been shown to be an effective technique for the therapy of Miller's class II and III GRs, allowing root coverage and increase of KT.

\section{CLINICAL RELEVANCE}

A surgical treatment for gingival recessions using the laterally positioned flap in two clinical cases provides aesthetic and functional increase, through root coverage and keratinized tissue augmentation, as shown in the clinical results. These cases report aims to contribute to the clinical practice of Periodontics, reporting that the described technique can be a good choice for cases of located gingival recessions.

\section{CONFLICTS INTERESTS}

There are not conflicts of interest or financial support for this study.

\section{References}

1. Cortellini P, Bissada NF. Mucogingival conditions in the natural dentition: Narrative review, case definitions, and diagnostic considerations. J Clin Periodontol. 2018; 45 (Suppl 20): 190-198.

2. Falabella MD, Alvarenga FFN, Segalla KBT, Adão SRL, Silva DG, SilvaBoghossian C. Treatment of gingival recession in 2 surgical stages: free gingival graft plus coronally positioned flap. Gen Dent. 2018; 66:58-61.

3. Zucchelli G, Mounssif I. Periodontal plastic surgery. Periodontol 2000. 2015 68:333-68

4. Chambrone L, Sukekava F, Araújo MG, Pustiglioni FE, Chambrone LA, Lima LA Root-coverage procedures for the treatment of localized recession-type defects: a Cochrane systematic review. J Periodontol. 2010; 81:452-478.

5. Tonetti MS, Jepsen S. Clinical efficacy of periodontal plastic surgery procedures: consensus report of Group 2 of the 10th European Workshop on Periodontology. J Clin Periodontol. 2014; 41:36-43.

6. Zucchelli G, Cesari C, Amore C, Montebugnoli L, De Sanctis M. Laterally moved, coronally advanced flap: a modified surgical approach for isolated recession-type defects. J Periodontol. 2004; 75:1734-41.

7. Ahmedbeyli C, Ipci SD, Cakar G, Yilmaz S. Laterally positioned flap along with acellular dermal matrix graft in the management of maxillary localized recessions. Clin Oral Invest. 2019; 23:595-601.

8. Chambrone L, Chambrone LA, Tatakis DN, Costa Hanemann JA, Shibli JA, Nevins M. Wound Healing os the laterally positioned flap a histomorphometric assessment. Int J Periodont Rest. 2015; 35: 785-792.

9. Chambrone LA, Chambrone L. Treatment of Miller Class I and II localized recession defects using laterally positioned flaps: A 24-month study. Am J Dent. 2009; 22: 339-344.
10. César Neto JB, Cavalcanti MC, Sekiguchi RT, Pannuti CM, Romito GA Tatakis DN. Root coverage for single deep gingival recessions: Outcomes based on a decision-making algorithm. Int J Dent. 2019 Jan; 2019:1830765. https:// doi. org/10.155/2019/183076.

11. Lee CT, Chang PC, Touchan N, Royzman D. Root coverage with a modified laterally positioned flap combined with a subepithelial connective tissue graft in advanced recession. J Periodontal Implant Sci. 2014; 44: 300-306.

12. Chambrone L, Chambrone D, Pustiglioni FE, Chambrone LA, Lima LA. Can subepithelial connective tissue grafts be considered the gold standard procedure in the treatment of Miller Class I and II recession-type defects? J Dent. 2008; 36:659671.

13. Edel A. Clinical evaluation of free connective tissue grafts used to increase the width of keratinized gingiva. J Clin Periodontol. 1974; 1:185-196.

14. Chopra DK, Kaushik M, Kochar D, Malik S. Laterally positioned flap - A predictable and effective periodontal procedure for the treatment of adjacent classIII gingival recession defect - case report. J Ind Dent Assoc. 2011; 5: 725-727. 15. Chambrone LA, Villa N, Cardoso RH, Lascala NT. Aspectos histopatológicos do tratamento de retrações gengivais localizadas, com retalho deslocado e associado ao uso de ácido cítrico. Rev Periodont. 1998; 7:61-5.

16. Caffesse RG, De La Rosa M, Garza M, Munne-Travers A, Mondragon JC Weltman R. Citric acid demineralization and subepithelial connective tissue grafts. J Periodontol. 2000; 71:568-572. 